Check for updates

Cite this: Chem. Sci., 2018, 9, 3570

\title{
Highly active nano-sized iridium catalysts: synthesis and operando spectroscopy in a proton exchange membrane electrolyzer
}

\author{
P. Lettenmeier, (iD a J. Majchel, (DD ${ }^{a}$ L. Wang, (DD ${ }^{a}$ V. A. Saveleva, ${ }^{\text {b }}$ S. Zafeiratos, (D) ${ }^{b}$ \\ E. R. Savinova, ${ }^{\text {b J.-J. Gallet, }}{ }^{\text {cd }}$ F. Bournel, ${ }^{\text {cd }}$ A. S. Gago (D) ${ }^{* a}$ and K. A. Friedrich ${ }^{a e}$
}

A stable and cost effective oxygen evolution reaction (OER) catalyst is crucial for the large-scale market penetration of proton exchange membrane (PEM) water electrolyzers. We show that the synthesis of iridium nanoparticles in either low purity ethanol or water, or in the absence of a surfactant, is detrimental to the electrocatalytic properties of the materials. Adding $\mathrm{NaBH}_{4}$ in excess improves the purity of the catalyst enhancing the OER activity up to $100 \mathrm{~A} \mathrm{glr}^{-1}$ at $1.51 \mathrm{~V}$ vs. RHE, the highest value reported so far for high purity Ir nanoparticles. The measured OER activity correlates with the capacitive

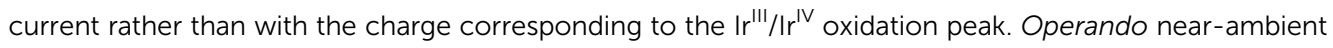
pressure X-ray photoelectron spectroscopy (NAP-XPS) on membrane electrode assemblies (MEAs) with the synthesized catalysts reveals a metallic core surrounded by a thin layer of $\mathrm{Ir}^{\mathrm{III/IV}}$ oxides/hydroxides. Oxidation of $\mid \mathrm{Ir}^{\mathrm{II}}$ leaves behind a porous ultrathin layer of $\mathrm{Ir}^{\mathrm{IV}}$ oxides/hydroxides, which dominate the surface during the OER, while $\operatorname{Ir}^{\vee}$ was not detected.

Received 2nd February 2018

Accepted 20th February 2018

DOI: $10.1039 / \mathrm{c} 8 \mathrm{sc} 00555 \mathrm{a}$

rsc.li/chemical-science

produced by electrolysis is a promising solution for storing renewable energy and can be used for producing synthetic fuels., ${ }^{\mathbf{4} 5}$ Proton exchange membrane (PEM) water electrolysis is particularly interesting for such purposes, due to the high dynamic operation and the ability for partial- and overload. These are outperforming properties in use for grid services. Currently, PEM electrolyzer systems have power capacities up to 1.5 MW and are installed in container solutions. ${ }^{6}$ PEM electrolyzer systems have power capacities up to $1.5 \mathrm{MW}$, with efficiencies above $70 \%$ and are installed in container solutions. ${ }^{6}$ In 2003, the estimated worldwide production of hydrogen was approx. $500 \mathrm{bn} \mathrm{Nm}^{3} \mathrm{a}^{-1} .^{7}$ The major part of this production is based on hydrocarbons such as steam methane reforming or coal gasification and yet, PEM electrolyzer facilities are far away from meeting the hydrogen demands of industrialized countries.

As an example, $5 \%$ of the annual hydrogen production in Germany requires the installation of about $1 \mathrm{GW}$ of PEM electrolyzers. ${ }^{8}$ The manufacture of 1 GW PEM electrolyzers would require approx. $0.6 \mathrm{t}$ of iridium (taking into account the standard loading of the oxygen catalyst) which is about $10 \%$ of the annual mining/production of the precious metal.,90

In terms of availability, the issue of using high loadings of Ir in membrane electrode assemblies (MEAs) is one of the most important research topics in PEM electrolysis. The target is to increase the electrocatalytic activity by the use of supporting materials, $\dagger^{11-16}$ changing the crystalline structure, ${ }^{17-19}$ optimizing the electrochemical active surface area $\mathrm{a}^{20-23}$ and to understand the degradation mechanism for such materials ${ }^{24,25}$ to decrease the required amount of Ir in highly efficient PEM electrolyzer systems. 
Recent publications show a clear trend from stoichiometric rutile-type $\mathrm{IrO}_{2}$ catalysts towards materials with metallic character, $\mathrm{IrO}_{x}$-Ir. Without subsequent thermal treatment, electrochemically oxidized Ir-based catalysts show several orders of magnitude higher oxygen evolution reaction (OER) activity compared to the thermally oxidized counterparts. In this context, the group of Strasser produced highly active nanodendrites ${ }^{13}$ as well as $\operatorname{IrNiO}_{x}$ core-shell catalysts ${ }^{26}$ with superior activity and reported a decreasing performance with increasing the temperature of heat treatment. Moreover, Pi et al. reported Ir 3D-nanostructures with excellent activity in the alkaline and acidic media. ${ }^{27}$

Besides the OER activity, the catalyst cost and the complexity of the synthesis have a significant impact on the choice of the catalyst material of future electrolyzers. Based on previous published work, ${ }^{22,28}$ the following publication presents a cost-efficient synthesis route for highly active Ir-nanoparticles and discusses the influence of the quality and costs of the participating chemicals. Furthermore, we discuss various approaches to evaluate the electrocatalytic activity of the catalysts and use operando as well as ex situ characterization methods to unveil their composition and structure and explain their enhanced OER activity.

\section{Experimental}

\section{Catalyst synthesis}

The herein presented catalysts are synthesized via a wet-chemical method shown in Fig. 1. To evaluate the influence of the solvent's purity, different grades are used for synthesis. Table 1 lists each investigated configuration. For producing iridium nanoparticles $5.625 \mathrm{~g}$ cetyltrimethylammonium bromide (CTAB) and $0.448 \mathrm{~g}$ iridium(III) chloride $\left(\mathrm{IrCl}_{3}\right)$ are dissolved in $540 \mathrm{ml}$ and $225 \mathrm{ml}$ ethanol (EtOH), respectively. After applying ultrasonication for $10 \mathrm{~min}$ each, the two solutions are mixed together using a magnetic stirrer (rotation speed at $480 \mathrm{rpm}, 30 \mathrm{~min}$ ). Meanwhile another solution of $0.684 \mathrm{~g}$ sodium borohydride $\left(\mathrm{NaBH}_{4}\right)$ as the reducing agent and $90 \mathrm{ml}$ ethanol is prepared with the assistance of an ultrasonication bath for $10 \mathrm{~min}$. The latter solution is added at $2-3 \mathrm{ml} \mathrm{min} \mathrm{m}^{-1}$ to the former which is additionally purged with argon and now mixed at $600 \mathrm{rpm}$. This causes an obvious reduction of $\mathrm{IrCl}_{3}$ within an hour coloring the solution from greenish to blackish. The rotation speed is maintained for 12 hours to ensure an entire reduction.
Afterwards, the as-synthesized particles are separated from the liquid phase by a centrifuge (4 min at $7600 \mathrm{rpm}$ ). For removing contaminations the powder is washed four times with ethanol and four times with deionized water as well. Finally, the wet powder is dried in a furnace at $40{ }^{\circ} \mathrm{C}$ under an air atmosphere. Deviating from the above mentioned synthesis route, a five-fold amount of $\mathrm{NaBH}_{4}$ was used for Ir-nano 99.8-P. Furthermore, high purity EtOH - in the case of Ir-nano 99.8 and 99.8-P - was only exposed to argon during the wet-chemical synthesis. For that all flasks were purged with argon before being sealed. In order to investigate the influence of the EtOH quality, different samples with different purities of the solvent were prepared and characterized afterwards. Table 1 summarizes the chemical precursors for the synthesis of the catalysts. The influence of the surfactant CTAB as well as the use of water as a solvent was investigated too.

\section{Physical characterization}

Scanning electron microscopy images were produced by using a Zeiss ULTRA plus with charge compensation in order to get information about the morphology of the catalysts. Detection of secondary electrons (SEs) and backscattered electrons (BSEs) with an accelerating voltage of $1 \mathrm{kV}$ allows distinguishing different materials. Integrated energy-dispersive X-ray spectroscopy (EDX) was used for elemental analysis of the measured powders. At least eight measurements were recorded for each material. Samples for transmission electron microscopy (TEM) are prepared by dispersing the catalyst powder in ethanol and applied on the carrier by use of a pipette. This sample pad of type S160 from Plano consists of a 10-15 nm thin carbon film, which is coated on a copper mesh 200 . The samples were examined by use of a TEM Philips CM200 FEG and an acceleration voltage of $200 \mathrm{kV}$. The software Digital Micrograph was used to analyze the images. Scanning transmission electron microscopy (STEM) was performed on the Ir nanoparticles scratched from the MEA after NAP-XPS measurements. A LaB6-JEOL 2100 microscope operating at $200 \mathrm{kV}$ and with a point to point resolution of $0.1 \mathrm{~nm}$ was used. The Fast Fourier Transformation (FTT) analysis was performed using the Digital Micrograph software.

\section{Electrochemical measurements and RDE preparation}

All electrochemical measurements are performed in $0.5 \mathrm{M}$ $\mathrm{H}_{2} \mathrm{SO}_{4}$ by a rotating disk electrode (PINE Research
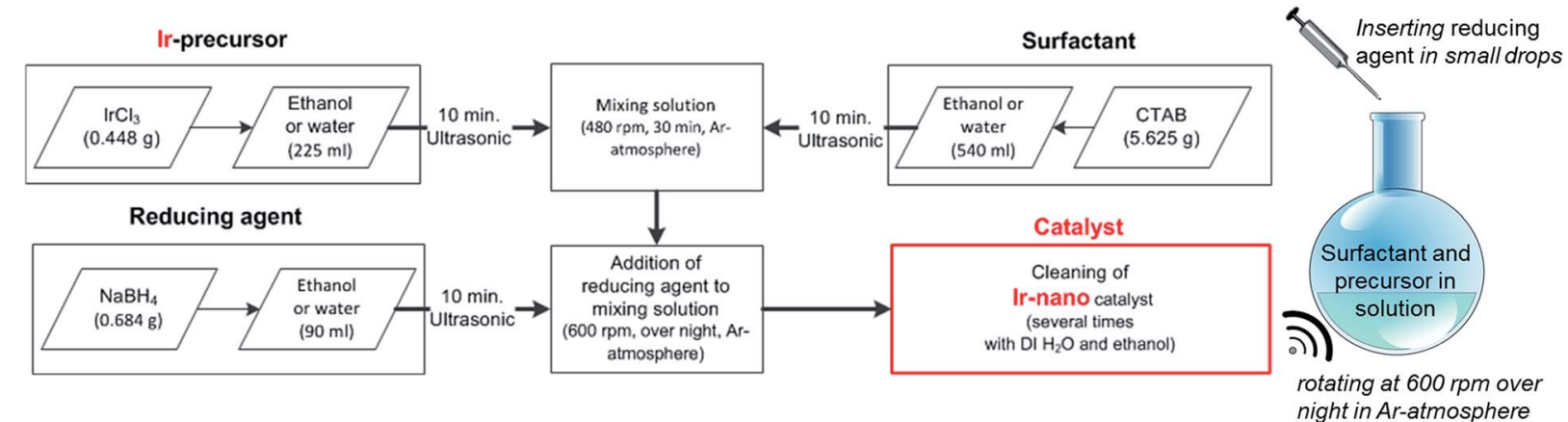

Fig. 1 Scheme of the chemical synthesis procedure of Ir nanoparticles. 
Table 1 Precursors for the synthesis of Ir nanoparticles (Ir-nano)

\begin{tabular}{|c|c|c|c|}
\hline Catalyst name & Solvent & Reductant & Ir precursor \\
\hline Ir-nano 99.8 & $\geq 99.8 \%$ pure $\mathrm{EtOH}^{a}$ & $1 \times \mathrm{NaBH}_{4}$ & $\mathrm{IrCl}_{3}{ }^{b}$ \\
\hline Ir-nano 99.8-P & $\geq 99.8 \%$ pure EtOH & $5 \times \mathrm{NaBH}_{4}$ & $\mathrm{IrCl}_{3}$ \\
\hline Ir-nano 99.5 \CTAB & $\geq 99.5 \%$ pure EtOH, without $\mathrm{CTAB}^{d}$ & $1 \times \mathrm{NaBH}_{4}$ & $\mathrm{IrCl}_{3}$ \\
\hline Ir-nano 91.5 & $\geq 91.5 \%$ pure $\mathrm{EtOH}^{e}$ & $2 \times \mathrm{NaBH}_{4}$ & $\mathrm{IrCl}_{3}$ \\
\hline Ir-nano $\mathrm{H}_{2} \mathrm{O}$ & DI water $\mathrm{H}_{2} \mathrm{O}^{f}$ & $2 \times \mathrm{NaBH}_{4}$ & $\mathrm{IrCl}_{3}$ \\
\hline
\end{tabular}

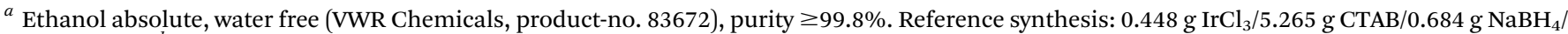
$855 \mathrm{ml} \mathrm{EtOH.}{ }^{b}$ Iridium(III)-chloride, dried, min. 62\% Ir (Alfa Aesar, product-no. 12158). ${ }^{c}$ Ethanol absolute (VWR Chemicals, product-no. 20816), purity $\geq 99.5 \%$. ${ }^{d}$ Cetyltrimethyl ammonium bromide (VWR Chemicals, product-no. 22610.132). ${ }^{e}$ Ethanol 99\% (VWR Chemicals, product-no. 84835), purity $\geq 91.5 \%$. ${ }^{f}$ Water (VWR Chemicals, product-no. 90200 ), conductivity $\leq 1.1 \mu \mathrm{S} \mathrm{cm}^{-1}$.

Instrumentation) method using a Metrohm Autolab PGSTAT12 in potentiodynamic mode. A platinum wire acts as the counter electrode and a reversible hydrogen electrode (HydroFlex by Gaskatel) as the reference electrode. The ohmic drop is determined by electrochemical impedance spectroscopy (EIS) making use of a second potentiostat (IM6 by ZahnerElektrik).

To produce a catalyst ink $10 \mathrm{mg}$ powder is added to $8.3 \mathrm{ml}$ ultra-pure water and $40 \mu \mathrm{l}$ Nafion resin being subsequently sonicated in an ice bath for $30 \mathrm{~min}$. After brief electrode polishing with $0.05 \mu \mathrm{m}$ aluminum suspension, $10 \mu \mathrm{l}$ ink is dropcast onto a glassy carbon disk (diameter of $5 \mathrm{~mm}$ ) resulting in a loading of $6.1 \times 10^{-5} \mathrm{~g}_{\mathrm{Ir}} \mathrm{cm}^{-2}$. Afterwards, the coating is dried under an inert gas atmosphere. Ir-black by Umicore is used as the reference catalyst.

Before starting the measurement the electrolyte $(0.5 \mathrm{M}$ $\mathrm{H}_{2} \mathrm{SO}_{4}$ ) is purged with $\mathrm{N}_{2}$ for at least $10 \mathrm{~min}$. In the next step the coated electrode is mounted to the rotating unit and plunged into the sulfuric acid. All cyclic voltammetries (CV) are performed at a rotation speed of $2300 \mathrm{rpm}$ and an electrolyte temperature of $25{ }^{\circ} \mathrm{C}$. Moreover, the gas supply is not interrupted during measurements.

Table S1 $\uparrow$ shows the different protocols of $\mathrm{CV}$ applied consecutively to evaluate the OER activity (CV1), to clean the surface (CV2) and to determine the turnover frequency (TOF) from the $\mathrm{Ir}^{\mathrm{III}} / \mathrm{Ir}^{\mathrm{IV}}$ redox peak (CV3). The results are corrected by taking ohmic losses (IR drop) and capacitive current into account.

MEAs having Ir-black (Umicore) and Ir-nano 99.8 anodes were prepared, and tests in the PEM electrolyzer stack were performed in order to obtain additional information about the functionality and stability of the catalysts. The MEAs were elaborated using the wet spraying technique from suspensions with the catalysts having the same proportion of solvents and Nafion ionomer. The results are presented in Fig. S7.†

\section{Operando near ambient pressure X-ray photoelectron spectroscopy (NAP-XPS)}

The XPS experiments were carried out at the NAP-XPS end station of the University Pierre et Marie Curie set on the TEMPO beamline $^{29}$ of the SOLEIL synchrotron in France. The analysis chamber of the NAP-XPS is equipped with a SPECS Phoibos 150-
NAP hemispherical electron analyzer including an electrostatic lens system with four differential pumping stages allowing a working pressure up to 20 mbar. A windowless beamline entrance with 3 differential pumping stages secures the pressure of the beamline below a limit of $5 \times 10^{-8}$ mbar. The analyzer is equipped with a Delay Line detector from Surface Concept. The photon energy of the TEMPO beamline ranges from 40 to $1500 \mathrm{eV}$ with a resolution better than $70 \mathrm{meV}$. The spectra presented here were collected with pass energy of $50 \mathrm{eV}$, giving an overall resolution better than $0.15 \mathrm{eV}$ for all the photon energies used. The NAP-XPS chamber is also equipped with a quadrupole mass spectrometer in order to control the gas-phase composition of the chamber.

To study the electrocatalyst behavior under different polarization conditions the membrane electrode assemblies (MEAs) have been prepared by the catalyst-coated membrane method. The MEA preparation procedure was previously described..$^{30}$ The studies of Ir-nano 99.8 electrodes were performed at $3 \mathrm{mbar}$ oxygen-free water vapor pressure under a constant voltage applied between the working electrode (WE) and the counter electrode (CE), controlling the current values by means of chronoamperometry. The impedance spectroscopy measurements as well as other electrochemical techniques were performed using a $\mu$-Autolab potentiostat from Metrohm. The example of the CV obtained in the NAP-XPS chamber is shown in Fig. 8a. The XP spectra of the corresponding elements were recorded using the kinetic energy of the emitted photoelectrons of $c a .530 \mathrm{eV}$. For the depth profiling analysis the Ir $4 \mathrm{f} \mathrm{XP} \mathrm{spectra}$ were collected using the following photon energies: $460 \mathrm{eV}$, $595 \mathrm{eV}$ and $1080 \mathrm{eV}$. The corresponding inelastic mean free paths (IMFPs) of the emitted electrons were estimated using QUASES-IMFP-TPP2M software. The analysis depth was calculated as three times the IMFP and equaled 1.9, 2.3, and $3.6 \mathrm{~nm}$, respectively. The binding energy (BE) values were calibrated with respect to the $\mathrm{C} 1 \mathrm{~s}$ position $(284.8 \mathrm{eV})$. The peak fitting of $\mathrm{Ir}$ 4f XP spectra was performed based on Pfeifer et al. ${ }^{31}$ The spin orbit splitting as well as the area ratio between the $\operatorname{Ir} 4 \mathrm{f}_{7 / 2}$ and Ir $4 \mathrm{f}_{5 / 2}$ components was constrained to $3 \mathrm{eV}$ and $4: 3$, respectively. Shirley background was used for all the spectra. Curve fitting was performed based on a hybrid Doniach Sunjic/ Gaussian-Lorentzian (sum) function; for the details the reader should referred to ref. 31 . The assignment of Ir $4 \mathrm{f}$ components was done based on the literature data of the $\mathrm{BE}$ values 
summarized in Table S2 of the ESI. $\uparrow$ The analysis of O 1s XP spectra cannot be carried out due to the presence of Si-based species, most probably $\mathrm{SiO}_{x}$ originating from the membrane.

\section{Quantitative modeling of XP spectra}

To estimate the thickness of the formed $\mathrm{Ir}^{\mathrm{IV}}$ oxide layer in the OER region, the Ir $4 \mathrm{f}$ XP spectra were simulated using the SESSA software (Version 2.0). ${ }^{32}$ The modeling was carried out with a "layered sphere" morphology (Fig. S5 $\dagger$ ), consisting of an outer $\mathrm{Ir}^{\mathrm{IV}}$ oxide layer of various thicknesses (from $0 \mathrm{~nm}$ to $0.35 \mathrm{~nm}$ ) and inner Ir metal. The particle diameter was maintained constant at a $2 \mathrm{~nm}$ value corresponding to a mean diameter of Ir nanoparticles. The photon energies were varied according to the experimental values $(460 \mathrm{eV}, 595 \mathrm{eV}, 1080 \mathrm{eV})$ with the mean free paths calculated by the software. The results are shown in Fig. S6. $\dagger$

\section{Discussion of results}

\section{Morphology and nano-structure}

The morphology of the synthesized catalysts was studied by SEM. Micrographs recorded with the secondary electrons (SEs) revealed the topographic contrast of the different materials, while the back-scattered electrons (BSEs) allowed distinguishing the Ir nanoparticles from the traces of the $\mathrm{IrCl}_{3}$ precursor. The commercial Ir-black powder, Fig. 2a, showed a foam flakeshaped morphology with a large number of sheets, sharp corners and defects, which reflect the high surface area of the material. No impurities at the micro-scale could be observed from the BSE image of Fig. 2b. In contrast, the material synthesized in aqueous medium, Ir-nano $\mathrm{H}_{2} \mathrm{O}$, shows particle agglomerates deposited on much larger crystals of another material (Fig. 2c), which could be clearly visualized by TEM and identified as unreduced $\mathrm{IrCl}_{3}, c f$. Fig. $3 \mathrm{~b}$ and $\mathrm{c}$.
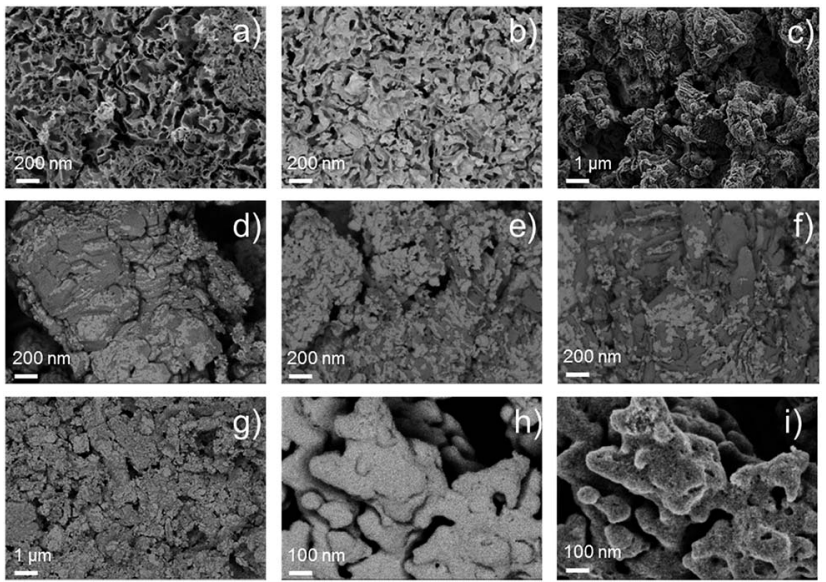

Fig. 2 SEM images from the secondary and back-scattered electron signals (SE, BSE) of catalysts (a) SE Ir-black and (b) BSE Ir-black; (c) SE Ir-nano $\mathrm{H}_{2} \mathrm{O}$; (d) BSE Ir-nano 91.5; (e) BSE Ir-nano 99.5\CTAB; (f) BSE Ir-nano 99.5; (g) BSE Ir-nano 99.8; and (h) BSE Ir-nano 99.8-P, (i) SE Irnano 99.8-P.
XRD patterns on the synthesized materials clearly show that the large crystals shown in Fig. 3b-f correspond to $\mathrm{IrCl}_{3}$ (monoclinic, $C 2 / m, 12$ ). Furthermore, the intensity of the peak situated at $29.5^{\circ}$ and $34.9^{\circ}$, which corresponds to the planes (130) and (131), respectively, is inversely proportional to the mass ratio $\mathrm{Ir} / \mathrm{Cl}$ measured with EDX, which will be discussed later. These results have been included in the ESI (Fig. S0 $\dagger$ ).

The BSE images, Fig. $2 \mathrm{~d}-\mathrm{g}$, of the catalysts synthesized with different EtOH purities clearly show the presence of $\mathrm{IrCl}_{3}$, which remained in the catalysts even after repetitive steps of cleaning with $\mathrm{H}_{2} \mathrm{O}$. We assume that it is the high coverage of $\mathrm{IrCl}_{3}$ crystals with Ir nanoparticles, Fig. $2 \mathrm{~g}$, which hinders the dissolution of the salt. Adding $\mathrm{NaBH}_{4}$ in the synthesis pot in a 20 -fold excess allows reducing the $\mathrm{IrCl}_{3}$ almost completely, Fig. $2 \mathrm{~h}$, producing a unique nano-porous catalyst with high rugosity, Fig. $2 \mathrm{i}$.

TEM micrographs and electron diffraction (ED) patterns confirm the nano-structure of the synthesized materials. Fig. 3a-f show the TEM images of the Ir-black and Ir-nano materials, arranged in a similar order as in Fig. 2. The ED patterns are presented as an inset for each image. The first and the brightest ring of the ED corresponds to the (111) reflection, followed by (002), (022), (311), and (222) reflections of the facecentered-cubic (fcc) structure of metallic iridium.

As shown in Fig. $2 \mathrm{~d}-\mathrm{g}$, the presence of large laminar $\mathrm{IrCl}_{3}$ crystals is visible for the material synthesized in $\mathrm{H}_{2} \mathrm{O}$, Fig. $3 \mathrm{~b}$, their occurrence diminishing as either the purity of EtOH, Fig. $3 \mathrm{c}-\mathrm{f}$, or the amount of reducing agent, Fig. $3 \mathrm{~g}$ and $\mathrm{h}$, is increased. These results were confirmed by X-ray diffraction (XRD), Fig. S0.† Fig. 3i represents a typical Ir particle size distribution for the purest and cleanest sample, Ir-nano 99.8-P.
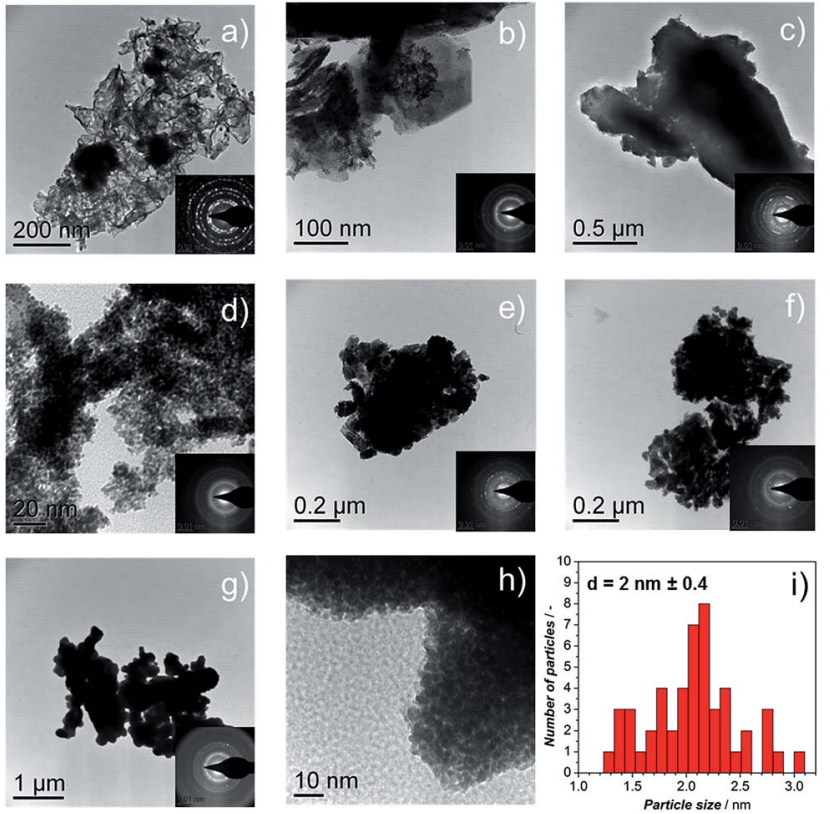

Fig. 3 TEM images of catalysts (a) Ir-black; (b) Ir-nano $\mathrm{H}_{2} \mathrm{O}$; (c) Ir-nano 91.5; (d) Ir-nano 99.5\CTAB; (e) Ir-nano 99.5; (f) Ir-nano 99.8; and (g), (h) Ir-nano 99.8-P; the insets show the electron diffraction pattern from the synthesized materials showing the (111), (002), (022), (311), and (222) reflections of metallic Ir. (i) Histogram of Ir-nano 99.8-P. 
Note that the average Ir particle size of $2 \pm 0.4 \mathrm{~nm}$ showed little dependence on the sample purity.

Post-mortem STEM analysis of the MEAs was carried out to determine the morphological changes in the Ir-nano catalysts after they were subjected to the OER. Fig. 4 shows a typical image acquired for the Ir-nano 99.8 electrode after operation. One may see that Ir nanoparticles are assembled in loose and highly porous agglomerates. This nanoporous morphology is preserved even after the electrochemical oxidation of the metallic core in the MEAs and is likely to be responsible for the high activity of the Ir nanocatalysts. The average diameter of the Ir nanoparticles remained approximately the same as that before electrochemical oxidation (Fig. 3). The core of the particles is metallic as confirmed by the Fast Fourier Transformation (FFT), which shows (111) and (200) reflections of fcc Ir. The reason for observing only these most intense reflections in the FFT is related to the small area of the analyzed spot (comprising 1-3 nanoparticles) in high resolution STEM, whereby the ED patterns were taken from lower resolution TEM images, and thus correspond to a much larger area.

\section{Oxygen evolution reaction (OER) activity}

In order to investigate the influence of the different purities of ethanol to the point of replacement of the ethanol by water as well as the influence of the use of CTAB a thorough electrochemical characterization was performed. Fig. 5a presents the typical polarization curve for determining the activity of the different catalysts. As a commercial benchmark, Ir-black was used. Obviously, the use of ultra-pure water is not sufficient for the presented synthesis of OER catalysts and in what follows will not be considered due to its lack of performance. However, the presented figure shows the relationship of the purity of the ethanol and the activity for the OER. The synthesis with the cheapest ethanol and the purity of $91.5 \%$ also yields the catalyst with the lowest performance followed by the synthesis with EtOH 99.5 without CTAB which has apparently a positive impact on the catalyst performance. Certainly, the choice of the EtOHquality achieves an optimum in the tradeoff between activity and costs. The activity of the Ir-nano catalysts synthesized with CTAB and EtOH 99.5, which is half as expensive as EtOH 99.8, the qualitatively best ethanol used, is within the error bar of Irnano 99.8 from our reference synthesis.
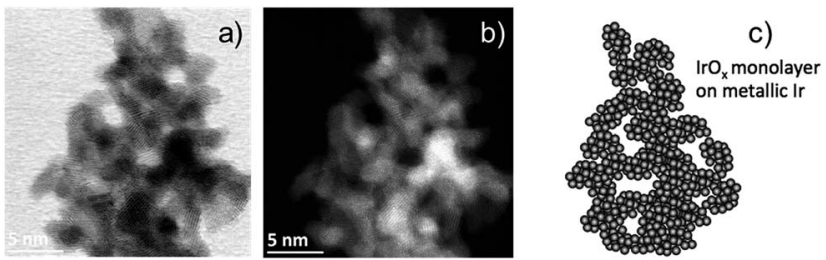

Fig. 4 (a) and (b) STEM images of the Ir nanoparticles from the Ir-nano 99.8 electrode after the OER (performed in the chamber of the NAPXP spectrometer). (c) Schematic illustration of the Ir-atoms forming nanoparticles interconnected based on the overall results from the physical characterization.
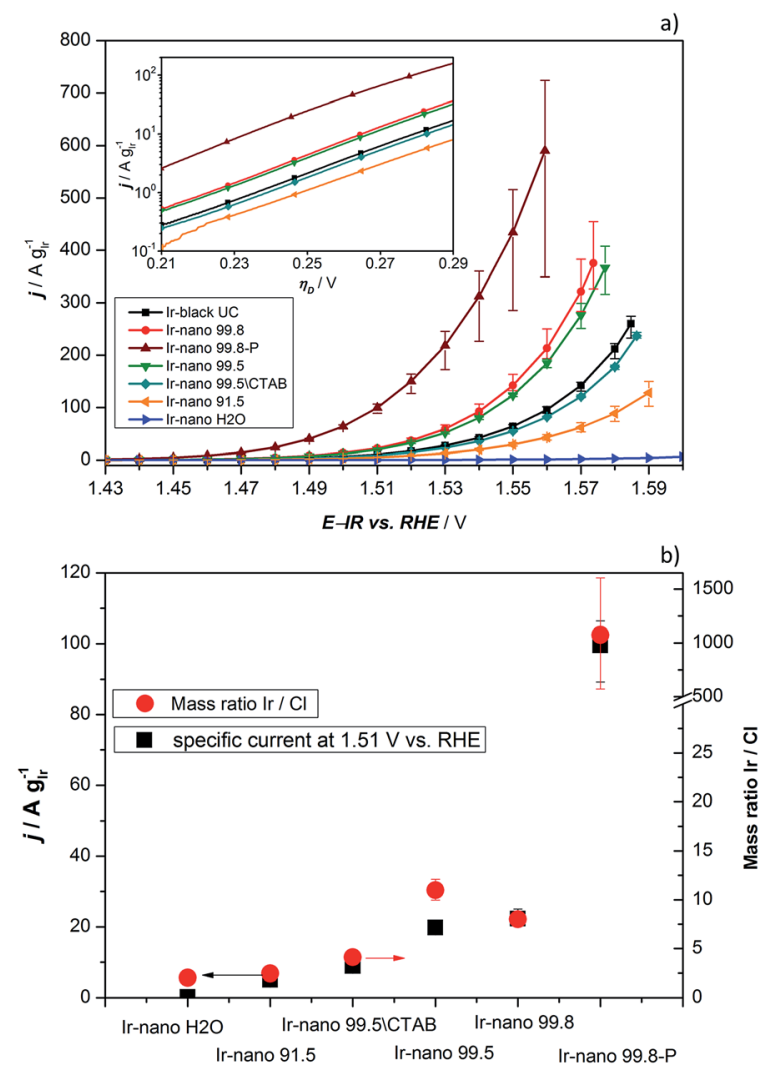

Fig. 5 (a) OER activity of all compared catalysts. The scanning rate, temperature and rotation speed are $5 \mathrm{mV} \mathrm{s}^{-1}, 25^{\circ} \mathrm{C}$, and $2300 \mathrm{rpm}$, respectively. The measurements were performed in $0.5 \mathrm{M} \mathrm{H}_{2} \mathrm{SO}_{4}$ and Ar-saturated solution; the inset shows the data as Tafel plots; (b) specific current density at $1.51 \mathrm{~V}$ vs. RHE measured under the same experimental conditions. The right axis indicates the $\mathrm{Ir} / \mathrm{Cl}$ mass ratio recorded by EDX.

It is thus clear that the impurities in the solvent such as water react with the reducing agent, which justifies the need for adding it in a 4-fold excess during the synthesis. However, even this excess seems to be insufficient for a complete reduction of the precursor $\mathrm{IrCl}_{3}$ since $\mathrm{Cl}$ impurities may be detected even in the Ir-nano 99.8 sample. With decreasing the solvent purity, the proportion of the $\mathrm{Cl}$ increases (EDX analysis). Fig. 5b presents a relationship between the $\mathrm{Ir} / \mathrm{Cl}$ mass ratio and the mass activity at $1.51 \mathrm{~V}$ vs. RHE. By increasing the amount of the reducing agent five-fold it was possible to increase the $\mathrm{Ir} / \mathrm{Cl}$ mass ratio by three orders of magnitude, resulting in the mass activity of $100 \mathrm{~A} \mathrm{~g}_{\mathrm{Ir}}{ }^{-1}$ at $1.51 \mathrm{~V}$ vs. RHE for Ir-nano 99.8-P, which is the highest OER activity so far reported for a pure Ir catalyst. This exceptional activity may be attributed to the small $(c a .2 \mathrm{~nm})$ particle size of Ir nanoparticles, a unique nanoporous morphology, which is preserved even after the OER, as well as to the small thickness of the oxide layer on the surface of Ir nanoparticles (vide infra). The fact that lower purity Ir-nano samples show significantly lower activity may be attributed to the presence of unreacted $\mathrm{IrCl}_{3}$ crystals, which impede electron transfer from Ir nanoparticles during the OER.

Since we use variations of the same synthesis route we can directly compare electrochemical parameters for various 
samples. The overpotential $\eta_{\mathrm{A}}$ shown in Fig. 5a can be described as follows: ${ }^{33}$

$$
\eta_{\mathrm{A}}=(2.303 R T / \alpha F) \log \left(j / j_{0}\right)
$$

where $T$ is the temperature, $R$ the ideal gas constant, $\alpha$ the apparent transfer coefficient, $F$ is the Faraday constant (96 $485 \mathrm{C} \mathrm{mol}^{-1}$ ), and $j$ is the current density. The mass-specific exchange current density $\left(j_{0}\right.$, intercept at $\left.\eta_{\mathrm{A}}=0\right)$ and the Tafel slopes $b$ can be determined from the linear parts of the curves represented in the inset of Fig. 5a (Tafel plots). Those electrochemical parameters, together with other important parameters which can be extracted from Fig. 5 and 6, are summarized in Table 2 and are worthy to be discussed. The Tafel slope was fitted for all catalysts with EtOH at overpotentials between 230 and $260 \mathrm{mV}$. The Tafel slopes and the corresponding apparent transfer coefficients $\alpha$ are close to the values of $40 \mathrm{mV} \mathrm{dec}^{-1}$ and 1.5 , respectively. These correspond to the second electron transfer as the rate determining step of the OER mechanism for $\mathrm{IrO}_{2}$ according to the Krasil'shchikov path..$^{35,36}$ The authors, however, pointed out that the graphical evaluation of the Tafel analysis can lead to misinterpretations of the specific exchange current density due to the nature of the graphical analysis and the extrapolation which are difficult to avoid. Therefore, due to the extrapolation to zero overpotential, small changes at the Tafel

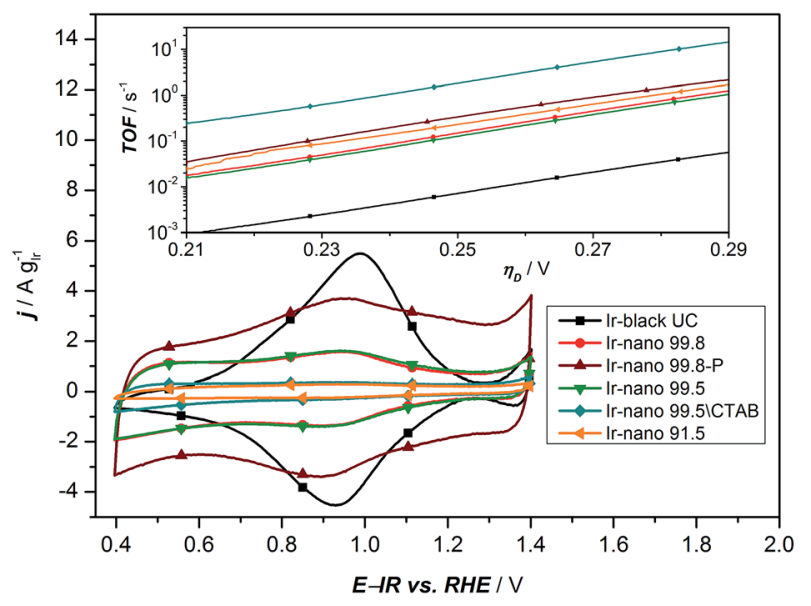

Fig. 6 Cyclic voltammetry of all synthesized materials with different purities of EtOH. The inset presents the calculated TOF based on the analysis of the redox peaks of the CV. slope lead to unexpected behavior of the exchange current densities. The Tafel slope of the Ir-nano 99.8-P catalyst is in fact the closest to the theoretical value, but for the other catalysts, the impurities can affect the porosity of the electrode influencing the Tafel slope and $\alpha .{ }^{37}$ Tafel slopes should be similar for all synthesis batches since the active component is assumed to be the same (cf. similar Ir particle size discussed above) and changes in the OER activity are related to the corresponding number of active sites. This supports the observation that Ir nanoparticles deposited on $\mathrm{IrCl}_{3}$ are not active due to poor electrical connection.

Comparing the activities of the catalysts, presenting specific current densities at reasonable potentials such as $1.48 \mathrm{~V}, 1.51 \mathrm{~V}$ or $1.56 \mathrm{~V} v s$. RHE is more meaningful as it is customary in the literature. ${ }^{\mathbf{1 1 - 1 3 , 2 2 , 2 6 , 3 4}}$

As a characteristic footprint, CVs before the OER region and between 0.4 and $1.4 \mathrm{~V} v s$. RHE demonstrate the first significant differences between the reference catalyst Ir-black and the synthesized Ir-nano catalysts. In Fig. 6, all CVs are presented. Even if all catalysts have similar physical properties and a metallic core surrounded by a thin oxide/hydroxide layer, ${ }^{22}$ as reported for the most recently published highly active Ir based catalysts, ${ }^{11,18,22,38}$ a distinctive redox peak of $\operatorname{Ir}^{\mathrm{III}}$ to $\operatorname{Ir}^{\mathrm{IV}}$ can mainly be observed for Ir-black. This redox peak can be used for calculating the turnover frequency (TOF) with respect to the overpotential, ${ }^{11,22,39}$ which is presented in the inset of Fig. 6 and calculated as follows.

$$
\mathrm{TOF}=j /\left(z N_{\mathrm{s}} Q_{\mathrm{e}^{-}}\right)
$$

Under the assumption that the OER occurs on the same sites, which are involved in the $\mathrm{Ir}^{\mathrm{III}}$ to $\mathrm{Ir}^{\mathrm{IV}}$ redox transition, ${ }^{34}$ the charge under the $\mathrm{Ir}^{\mathrm{III}} / \mathrm{Ir}^{\mathrm{IV}}$ redox peak can be considered as a measure of the number of active sites $N_{\mathrm{s}}$ multiplied by the electron charge $Q_{\mathrm{e}^{-}}$. Due to the small redox peaks of the Ir-nano catalysts, the correct analysis of the TOF is challenging. These peaks are illdefined probably due to a high surface heterogeneity and presence of slightly shifted peaks for various surface sites. The TOF for the synthesis without CTAB is unexpected but precisely the highest. This is most likely caused by an inaccurate analysis of an almost non-existing redox peak. The TOF of all synthesized materials is expected to be in the same range. Clearly divergent is the TOF of Ir-black due to the relatively low current density and the distinctive $\mathrm{Ir}^{\mathrm{III}} / \mathrm{Ir}^{\mathrm{IV}}$ redox peak, which indicates a large number of active sites. Obviously, the absence of the correlation with the charge of the redox peak and the activity suggests that

Table 2 Electrochemical parameters

\begin{tabular}{lcccccc}
\hline Ink & $j_{1.48 \mathrm{~V}}\left[\mathrm{~A} \mathrm{~g}_{\mathrm{Ir}}^{-1}\right]$ & $j_{1.51 \mathrm{~V}}\left[\mathrm{~A} \mathrm{~g}_{\mathrm{Ir}}^{-1}\right]$ & $b\left[\mathrm{mV} \mathrm{dec}^{-1}\right]$ & $\alpha[-]$ & $j_{0} \times 10^{-6}\left[\mathrm{~A} \mathrm{~g}_{\text {Ir }}^{-1}\right]$ & $j_{\text {cap }} \times 10^{-1}\left[\mathrm{~A} \mathrm{~g}_{\text {Ir }}^{-1}\right]$ \\
\hline Ir-black UC & 2.2 & 10.4 & 42.9 & 1.38 & 3.16 & 3.55 \\
Ir-nano 99.8 & 4.4 & 22.3 & 41.2 & 1.44 & 3.79 & 6.99 \\
Ir-nano 99.8-P & 24.2 & 99.6 & 39.7 & 1.49 & 13.50 & 26.74 \\
Ir-nano 99.5 & 3.9 & 19.8 & 41.7 & 1.42 & 3.93 & 7.67 \\
Ir-nano 99.5\CTAB & 1.8 & 8.9 & 42.7 & 1.38 & 2.57 & 2.99 \\
Ir-nano 91.5 & 1.1 & 5.1 & 46.4 & 1.28 & 4.48 & -12 \\
Ir-nano $\mathrm{H}_{2} \mathrm{O}$ & 0.1 & 0.3 & 63.8 & 0.93 & 9.92 &
\end{tabular}


this analysis method does not provide realistic information relative to the number of active sites. Therefore this method cannot be used for determining the active sites which are necessary for calculating the TOF.

However, Fig. 7 presents the comparison between the OER activity and the capacitive current between $1.26 \mathrm{~V}$ and $1.3 \mathrm{~V}$ of Fig. 6, where no faradaic processes are expected.

The measured activity correlates well with the capacitive current (correlation coefficient: 0.994), suggesting that the latter provides a realistic access to the surface area, and that all samples have the same state of surface. Therefore the main reason for the high activity of the materials is the small particle size, yet the overall performance of the catalyst layer is greatly affected by the presence of $\mathrm{IrCl}_{3}$ impurities. Further information about the surface state of Ir nanoparticles during the OER will be provided by NAP-XPS measurements performed under operando conditions.

\section{Operando NAP-XPS analysis}

To provide insight into the exceptional OER activity of Irnanocatalysts compared to the state-of-the-art Ir-based materials we apply NAP-XPS and follow the surface composition of Irnano electrodes depending on the polarization. Considering similarities in the electrocatalyst synthesis and structure, only the Ir-nano 99.8 catalyst was investigated. The measurements were performed at ambient water vapor pressure in a twoelectrode configuration with MEAs consisting of an Ir-nano anode (working electrode, WE) and a Pt/C cathode (counter electrode, CE; see Experimental). Before the NAP-XPS measurements, the surface of the Ir-nano 99.8 was stabilized by applying a few potential cycles in the interval of $-0.25 \mathrm{~V} \leq$ $U_{\mathrm{WE}-\mathrm{CE}} \leq 1.0 \mathrm{~V}$, where $U_{\mathrm{WE}-\mathrm{CE}}$ is the voltage applied between the WE and the CE. Fig. 8a shows a typical CV acquired in the measurement chamber of the XPS spectrometer. Compared to its counterpart acquired in a three-electrode liquid electrolyte cell, the CV is distorted, which may be attributed to a nonnegligible overpotential at the CE. Nevertheless, it shows a characteristic anodic peak at $c a$. $U_{\mathrm{WE}-\mathrm{CE}}=-0.25 \mathrm{~V}$ (commonly

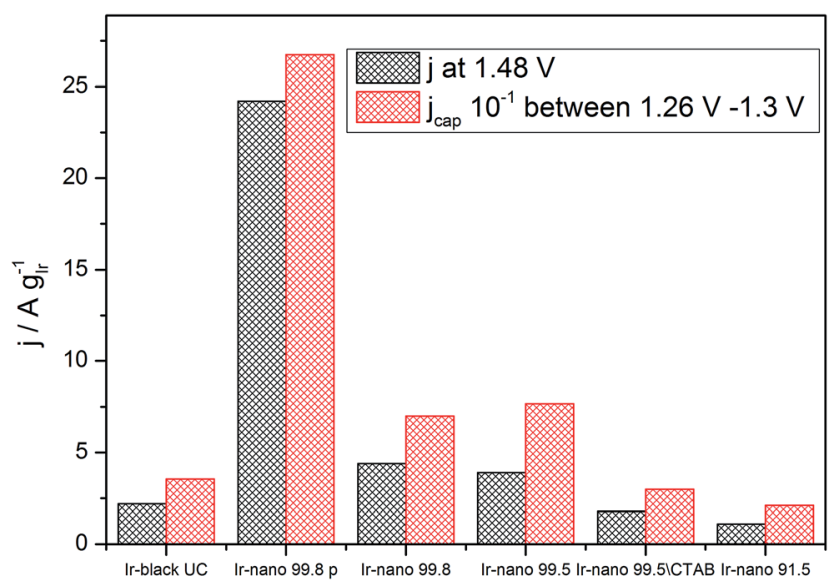

Fig. 7 Correlation between specific average capacitive current and specific activation current density at $1.48 \mathrm{~V}(250 \mathrm{mV}$ overpotential). attributed to the $\mathrm{Ir}^{\mathrm{III}} / \mathrm{Ir}^{\mathrm{IV}}$ transition) and a current rise at high overpotentials, corresponding to the OER. Then, XP spectra were acquired under constant applied voltage $\left(U_{\mathrm{WE}-\mathrm{CE}}\right)$ of (i) -0.25 ; (ii) 0.85 ; (iii) 1.05 and (iv) $1.40 \mathrm{~V}$. These values of the applied voltage correspond to (i) the potential interval below the anodic peak attributed to the $\mathrm{Ir}^{\mathrm{III}} / \mathrm{Ir}^{\mathrm{IV}}$ transition $\left(U_{\mathrm{WE}-\mathrm{CE}}=\right.$ $-0.25 \mathrm{~V})$; (ii) the potential region above the anodic peak $\left(U_{\mathrm{WE}-\mathrm{CE}}\right.$ $=0.85 \mathrm{~V})$; (iii) the OER onset $\left(U_{\mathrm{WE}-\mathrm{CE}}=1.05 \mathrm{~V}\right)$ and (iv) the OER $\left(U_{\mathrm{WE}-\mathrm{CE}}=1.40 \mathrm{~V}\right)$. The OER was confirmed by the mass spectrometer integrated in the measurement chamber (the results are not shown) and the current transients shown in Fig. $\mathrm{S} 1, \dagger$ which demonstrate steady-state OER currents at $U_{\mathrm{WE}-\mathrm{CE}}=1.05$ and $1.40 \mathrm{~V}$.

Ir $4 \mathrm{f}$ XP spectra at different applied potentials are displayed in Fig. 8b-e. The fitting of the spectra was performed using three doublets with Ir $4 \mathrm{f}_{7 / 2}$ peak positions at 61.0, $62.1 \pm 0.1$, and $62.8 \pm 0.1 \mathrm{eV}$, attributed to metallic $\operatorname{Ir}$, $\operatorname{Ir}^{\mathrm{IV}}$ and $\operatorname{Ir}^{\mathrm{III}}$, respectively. In the case of $\operatorname{Ir}^{\mathrm{III}}$ and $\operatorname{Ir}^{\mathrm{IV}}$ satellite peaks at $64.6 \pm$ 0.1 and $63.4 \pm 0.1 \mathrm{eV}$, respectively, were used for fitting (see Table $\mathbf{S} 2$ for the BEs of reference compounds in the ESI $\dagger$ ). The voltage dependence of the contributions of various surface species is shown in panel (f) of Fig. 8. One may see that the Irnano electrode subjected to $\mathrm{CV}$ cycles shows both oxide $\left(\mathrm{Ir}^{\mathrm{III}}\right.$ and $\operatorname{Ir}^{\mathrm{IV}}$ ) and metallic species. Furthermore, by applying operando XPS, under the potential control and during the OER, we
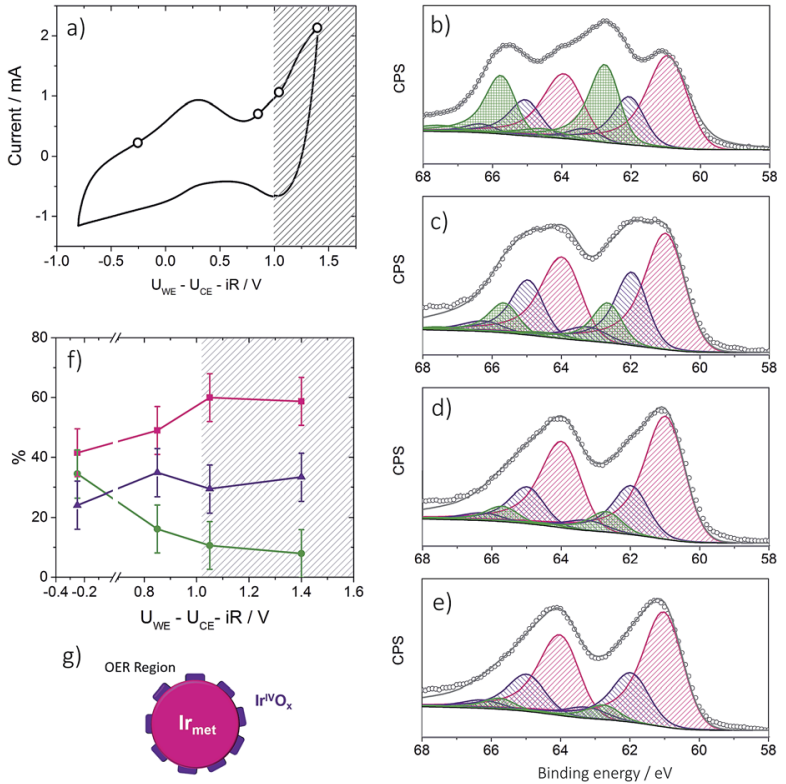

Fig. 8 Panel (a): CV acquired in the analysis chamber of the NAP-XP spectrometer at 3 mbar water vapor pressure. Currents are plotted vs. ohmic drop corrected $U_{\text {WE-CE. }}$ (b)-(e): Ir $4 f$ XP spectra of the Ir-nano 99.8 electrode obtained at 3 mbar water vapor pressure and under different polarization conditions $\left(U_{\mathrm{WE}-\mathrm{CE}}\right)$ : $-0.25 \mathrm{~V}(\mathrm{~b}) ; 0.85 \mathrm{~V}(\mathrm{c})$; $1.05 \mathrm{~V}$ (d); $1.4 \mathrm{~V}$ (e). Color codes: $\mid \mathrm{r}_{\text {met }}$ (magenta); $\mid r^{\mathrm{III}}$ (olive); $\mid r^{\mathrm{IV}}$ (violet), fitted line (grey). The raw data are presented as open circles. Photon energy $595 \mathrm{eV}$; panel (f): potential dependence of Ir components: $I r_{\text {met }}$ (magenta); Ir III (olive); Ir IV (violet) for the Ir-nano 99.8 electrode. The hatched area corresponds to the OER region marked according to the MS data. Temperature $25^{\circ} \mathrm{C}$; panel (g): scheme illustrating a tentative structure of the $\mathrm{IrO}_{x}$ layer on the surface of Ir nanoparticles. 
were able to observe the changes in the oxidation state of Ir with the applied potential. Indeed, one may clearly see that at potentials below the anodic peak in the CV of Fig. 8a, all three components, namely $\mathrm{Ir}_{\text {met }}$, $\mathrm{Ir}^{\mathrm{III}}$ and $\mathrm{Ir}^{\mathrm{IV}}$, are present in the XP spectrum, whereas increasing the cell voltage above $0.85 \mathrm{~V}$ leads to the disappearance of $\mathrm{Ir}^{\mathrm{III}}$ sites such that in the OER potential interval the surface and the near-surface region of the electrode only contains metallic Ir and $\mathrm{Ir}^{\mathrm{IV}}$ oxide (the contribution of the $\mathrm{Ir}^{\mathrm{III}}$ species above $1.0 \mathrm{~V}$ falling below the uncertainty level of XPS as one can see from Fig. 8f). Two different Ir-nano-based MEAs were studied and showed similar behavior (see Fig. S3, ESI $\dagger$ ), confirming the reproducibility of the measurements and the data analysis.

Tuning the photon energy (see Fig. S3†) resulted in small changes in the contributions of metallic $\operatorname{Ir} \operatorname{Ir}^{\mathrm{IV}}$ and $\mathrm{Ir}^{\mathrm{III}}$, thus not supporting a core-shell morphology and rather suggesting that oxidation of Ir nanoparticles results in the formation of a thin porous $\operatorname{Ir}^{\mathrm{III}} / \mathrm{Ir}^{\mathrm{IV}}$ layer on the surface. Once $\operatorname{Ir}^{\mathrm{III}}$ is oxidized, the surface of Ir nanoparticles is dominated by $\operatorname{Ir}^{\mathrm{IV}}$. The estimation of the Ir oxide thickness in the OER region $\left(U_{\mathrm{WE}-\mathrm{CE}}=1.40 \mathrm{~V}\right)$ was done using the SESSA software, simulating the XP spectra for the layered sphere morphology (see the ESI $\dagger$ ). Note that we only considered one type of Ir oxide, since as shown above, $\operatorname{Ir}^{\mathrm{III}}$ was fully converted into the $\operatorname{Ir}^{\mathrm{IV}}$ oxide during the OER (vide supra). Comparing the experimental and theoretical results, the apparent oxide thickness was estimated as $c a$. $0.2 \mathrm{~nm}$, which is comparable to a monolayer thickness. Considering all of the above we conclude that the Ir-nano catalyst, which is stabilized by potential cycling, consists of a metal core covered by a thin porous Ir oxide/ hydroxide layer. The composition of this oxide layer strongly depends on the applied potential and changes from a mixed $\mathrm{Ir}^{\mathrm{II}} / \mathrm{Ir}^{\mathrm{IV}}$ oxide/hydroxide below the OER onset to an $\operatorname{Ir}^{\mathrm{IV}}$ oxide monolayer above the OER onset, which further persists in the OER potential interval. This conclusion is in disagreement with the recent work of Minguzzi et al. ${ }^{34}$ who applied in situ Xray absorption spectroscopy (XAS) at the Ir- $\mathrm{L}_{\mathrm{III}}$ edge to investigate changes in the redox state of an $\mathrm{IrO}_{x}$ film prepared by chemical oxidation of $\mathrm{IrCl}_{3}$ by $\mathrm{H}_{2} \mathrm{O}_{2}$ and concluded on the coexistence of $\mathrm{Ir}^{\mathrm{III}}$ and $\mathrm{Ir}^{\mathrm{V}}$ during the OER. Note however that XPS is more sensitive to the changes in the oxidation state, and is also highly surface sensitive. The high surface sensitivity is confirmed by the data shown in Fig. 8 (panels b-e) whereby even a submonolayer coverage of Ir $^{\mathrm{III}}$ oxide/hydroxide can be clearly observed and followed as a function of the applied voltage. Thus, our data suggest that $\mathrm{Ir}^{\mathrm{III}}$ is absent from the particle surfaces under the OER conditions, and $\operatorname{Ir}^{\mathrm{III}}$ is oxidized to $\mathrm{Ir}^{\mathrm{IV}}$ below the OER onset. The $\mathrm{Ir}^{\mathrm{III}} / \mathrm{Ir}^{\mathrm{IV}}$ redox transition can be associated with the anodic peak observed at $U_{\mathrm{WE}-\mathrm{CE}}=0.25 \mathrm{~V}$ in the CV of Fig. 8a. This observation supports previous electrochemical studies, whereby $\operatorname{Ir}^{\mathrm{III}} / \mathrm{Ir}^{\mathrm{IV}}$ transition was postulated but not spectroscopically confirmed in situ. $^{24,25,40-42}$

An intriguing and highly debated question refers to the formation of Ir in oxidation state(s) above IV. Formation of $\operatorname{Ir}^{\mathrm{V}}$ under the OER conditions was postulated in early publications of Koetz ${ }^{\mathbf{4 3 4 4}}$ et al. and Pickup and Birss. ${ }^{41}$ Recently Casalongue et al. ${ }^{38}$ based on their NAP-XPS study suggested formation of $\operatorname{Ir}^{\mathrm{V}}$ during the OER on $\mathrm{IrO}_{2}$ oxide. This conclusion has been challenged by Pfeifer et al. ${ }^{31,45}$ who combined XPS measurements with DFT calculations to show that, due to the final state effects, the high BE component rather corresponds to $\operatorname{Ir}^{\mathrm{III}}$ species, and attributed the peaks observed in cyclic voltammetry at the OER onset to an anion $\mathrm{O}^{\mathrm{II}-} / \mathrm{O}^{\mathrm{I}-}$ rather than cation redox transition. Note also that the lack of either reliable $\mathrm{Ir}^{\mathrm{V}}$ reference data or theoretical calculations of the BE shifts for $\operatorname{Ir}^{\mathrm{V}}$ compounds complicates the debate around the formation of Ir OER intermediates in high oxidation state(s) (V or higher). While our recent work on mixed IrRu performed using operando NAP$\mathrm{XPS}^{30}$ did not confirm formation of any higher (than IV) oxidation states of Ir in the OER interval, one could argue that it was due to a relatively high $(530 \mathrm{eV})$ kinetic energy of photoelectrons. In this work we decreased the incident photon energy down to $460 \mathrm{eV}$ close to that used in ref. 38 (corresponding to Ir 4f photoelectrons with kinetic energy of $c a$. $395 \mathrm{eV}$ ) but did not observe appearance of any additional peaks in the Ir $4 \mathrm{f} \mathrm{BE}$ interval during the OER. Thus, this work does not support formation of Ir species in oxidation states different from IV under the OER conditions.

Another question concerns the nature of the $\operatorname{Ir}^{\mathrm{IV}}$ species formed on the surface of Ir nanoparticles during the OER. Even if the XPS is sensitive to the composition rather than the structure, analysis of the peak width of the Ir $4 \mathrm{f}$ doublet corresponding to $\mathrm{Ir}^{\mathrm{IV}}$ for the reference $\mathrm{IrO}_{2}$ samples with a rutile structure (see spectra in Fig. S2 $\dagger$ ) suggests that the $\operatorname{Ir}^{\mathrm{IV}}$ oxide film formed on Ir nanoparticles in this work is most likely amorphous rather than crystalline. Indeed, Pfeifer et al. ${ }^{31}$ demonstrated that crystalline and amorphous $\operatorname{Ir}^{\mathrm{IV}}$ oxides are characterized by different XP peak widths (FWHM). Formation of amorphous $\operatorname{Ir}^{\mathrm{IV}}$ oxide is in agreement with the monolayer thickness of the oxide film on metal Ir particles in this work. Thus, we conclude that the surface and subsurface composition of the Ir-nano electrode differs significantly from that observed for the rutile-type $\mathrm{IrO}_{2} \cdot{ }^{30}$ Indeed, Ir-nano consists of metallic Ir covered by a thin layer of $\mathrm{Ir}^{\mathrm{III} / \mathrm{IV}}$ (hydro)oxide below the OER onset, which is transformed into a monolayer of (amorphous) $\mathrm{Ir}^{\mathrm{IV}}$ oxide in the OER interval, while XP spectra of thermally obtained $\mathrm{IrO}_{2}$ oxide nanoparticles conform with crystalline rutile-type $\mathrm{IrO}_{2}$. It is interesting to note that the observed decrease of the contribution of the Ir $^{\mathrm{III}}$ component above $U_{\mathrm{WE}-\mathrm{CE}}=1.05 \mathrm{~V}$ is not accompanied by an increase in the contribution of the $\operatorname{Ir}^{\mathrm{IV}}$ component expected for an $\mathrm{Ir}^{\mathrm{III} / \mathrm{IV}}$ redox transition. Instead, the $\operatorname{Ir}^{\mathrm{IV}}$ component rests fairly independent of the applied voltage, while the Ir metal component increases slightly with the applied potential, which is counterintuitive (Fig. 8f). This experimental observation could be either attributed to the dissolution of Ir surface oxides, as previously reported by Cherevko et al. ${ }^{46}$ or to their transformation involving either changes of the oxide density or morphology. The former explanation seems unlikely on the time scale of our measurements considering the stable PEM electrolyzer operation of the prepared anodes for at least $100 \mathrm{~h}$ (Fig. S7†). Moreover, we have previously demonstrated in a commercial PEM electrolyzer that the degradation rates of MEAs with non-thermally oxidized Ir 
are sufficiently low for allowing long-term operation. ${ }^{47,48}$ Further stability tests with the developed catalysts are part of our ongoing work.

The XPS data do not allow distinguishing between the oxide thinning due to the transformation of hydrous into an anhydrous oxide or formation of a porous $\operatorname{Ir}^{\mathrm{IV}}$ oxide layer at high anodic potentials from a more compact $\mathrm{Ir}^{\mathrm{III} / \mathrm{IV}}$ film at lower potentials. The latter seems however more likely and is in good agreement with reports on Ir-black and Ir polished disc electrodes, which become porous under redox cycling, providing access to the metal underneath the surface oxide. ${ }^{23,40}$ Fig. $8 \mathrm{~g}$ provides an illustration of the tentative morphology of $\operatorname{Ir} / \mathrm{IrO}_{x}$ nanoparticles. The different surface composition/structure of Ir-nano compared to stoichiometric rutile-type $\mathrm{IrO}_{2}$ accounts for the significantly higher activity of the former.

Finally, the exceptionally high activity of Ir-nano 99.8-P compared to commercial Ir-black or other commercial Ir nanoparticles ${ }^{49}$ can be attributed to their nano-porous structure. Indeed, it has been reported that nano-porous dendritic structures of Ir supported on Vulcan XC-72 show 3-fold higher OER activity ${ }^{13}$ than Ir nanoparticles with similar particle size, $c a$. $2 \mathrm{~nm},{ }^{23}$ uniformly dispersed on the same support. Similarly, in PEM fuel cells it has been found that, after Ni leaching, the Ptrich $\mathrm{Pt}_{3} \mathrm{Ni}$ polyhedra (nano-frames) supported on carbon are much more active for the oxygen reduction reaction (ORR) than $\mathrm{Pt}_{3} \mathrm{Ni} / \mathrm{C}^{50,51}$ The leaching of an alloying element in the $\mathrm{IrO}_{\mathrm{x}}$ structure also leads to a substantial enhancement in catalytic activity. ${ }^{18,52}$ The STEM images of Fig. 4a and b show clearly a similar nano-porous morphology of unsupported Ir nanoparticles. Consequently, the fact that the Ir-nano material displays a 10-fold higher OER activity compared to that of the flake-like structured Ir-black cannot be attributed only to an increase in the surface area but is likely related to the nanoporous (nano-frame) structure of the Ir-nano catalyst. Similar to the $\mathrm{Pt}_{3} \mathrm{Ni}$ nano-frames, it is likely to be the large number of low-coordinated catalytic sites, corners, edges and defects in the Ir structure of Fig. 4 that lead to an unprecedented high atomic utilization. In this regard, this work fosters the scientific community to further investigate complex Ir-nanostructures with atomic level and in situ advanced spectroscopic techniques along with theoretical simulations.

\section{Conclusions}

In this study, the influence of varying the chemical purity and the concentration of the reducing agent on the electrocatalytic activity of synthesized Ir-nano particles is thoroughly explored.

The use of a tensioactive agent (in this case CTAB) is as important as the use of high purity solvents and the amount of reduction agent in excess. However, there is scope for cost reduction in the synthesis procedure with ethanol (99.5\%), which is half as expensive as $99.8 \%$ pure ethanol, resulting in similar electrocatalytic activity. Adding the reducing agent in excess enables almost complete elimination of $\mathrm{Cl}$ impurities in the final catalyst product and achieving an OER activity of $100 \mathrm{~A} \mathrm{~g}_{\mathrm{Ir}}{ }^{-1}$, measured for the first time at $1.51 \mathrm{~V} v s$. RHE.
The surface characterization of the Ir-nano electrode in the OER region performed by operando NAP-XPS revealed that electrochemical oxidation of Ir nanoparticles results in the formation of a monolayer-thick Ir oxide layer on the surface of metal particles. We also conclude that the $\mathrm{Ir}^{\mathrm{III}} / \mathrm{Ir}^{\mathrm{IV}}$ transition occurs below the OER onset, and under the OER conditions the surface is dominated by a thin amorphous $\mathrm{Ir}^{\mathrm{IV}}$ oxide layer. Thus, the superior activity of Ir-nano compared to thermally oxidized $\mathrm{IrO}_{2}$ catalysts may be attributed to the small ( $\mathrm{ca}$. monolayer thick) thickness of the oxide film and its interaction with the underlying metal core. The fact that we do not observe $\operatorname{Ir}^{V}$ species during the OER suggests that either they are not formed, or their coverage under steady-state measurement conditions is below the detection limit. In the future it might be interesting to perform time-resolved measurements in order to clarify whether $\operatorname{Ir}^{\mathrm{V}}$ or other Ir species with higher oxidation states are formed during the OER as short-lived intermediates.

\section{Conflicts of interest}

There are no conflicts of interest to declare.

\section{Acknowledgements}

The authors acknowledge the Federal Ministry for Economic Affairs and Energy (BMWi) for financial support in the project No. 0325440A. The research leading to these results has received funding from the European Union's Seventh Framework Program (FP7/2007-2013) for Fuel Cell and Hydrogen Joint Technology Initiative under Grant No. 621237 (INSIDE). The authors acknowledge Corinne Ulhaq-Bouillet (IPCMS, Strasbourg) for STEM characterization.

\section{Notes and references}

1 J. Rogelj, G. Luderer, R. C. Pietzcker, E. Kriegler, M. Schaeffer, V. Krey and K. Riahi, Nat. Clim. Change, 2015, 5, 519-527.

2 European Comission, Paris Agreement, 2017.

3 United Nations, Paris Agreement - Entry Into Force, 2016.

4 J. Nitsch, T. Pregger and T. Naegler, Langfristszenarien und Strategien für den Ausbau der erneuerbaren Energien in Deutschland bei Berücksichtigung der Entwicklung in Europa und global, 2012.

5 A. Sternberg and A. Bardow, Energy Environ. Sci., 2015, 8, 389-400.

6 B. Haubner, B. Pitschak, A. Bayer, A. Gago, P. Lettenmeier, V. Christoph and T. Smolinka, DVGW-Schriftenr., Gas, 2017, 3, 12-16.

$7 \mathrm{~J}$. Nitsch and M. Fischedick, Eine vollständig regenerative Energieversorgung mit Wasserstoff - Illusion oder realistische Perspektive, Wasserstofftag Essen, 2002, pp. 12-14.

8 P. C. K. Vesborg and T. F. Jaramillo, RSC Adv., 2012, 2, 7933.

9 C. Hagelüken, Metall, 2006, 60, 31-42.

10 G. B. Haxel, J. B. Hedrick and G. J. Orris, United States Geol. Surv. Fact Sheet, 2002, 087, p. 4. 
11 H. N. Nong, L. Gan, E. Willinger, D. Teschner and P. Strasser, Chem. Sci., 2014, 5, 2955.

12 L. Wang, P. Lettenmeier, U. Golla-Schindler, P. Gazdzicki, N. A. Cañas, T. Morawietz, R. Hiesgen, S. S. Hosseiny, A. S. Gago and K. A. Friedrich, Phys. Chem. Chem. Phys, 2016, 18, 4487-4495.

13 H.-S. Oh, H. N. Nong, T. Reier, M. Gliech and P. Strasser, Chem. Sci., 2015, 6, 3321-3328.

14 H. N. Nong, H. Oh, T. Reier, E. Willinger, M. Willinger, V. Petkov, D. Teschner and P. Strasser, Angew. Chem., Int. Ed., 2015, 2, 2975-2979.

15 L. Ma, S. Sui and Y. Zhai, J. Power Sources, 2008, 177, 470477.

16 L. Wang, F. Song, G. Ozouf, D. Geiger, T. Morawietz, M. Handl, P. Gazdzicki, C. Beauger, U. Kaiser, R. Hiesgen, A. S. Gago and K. A. Friedrich, J. Mater. Chem. A, 2017, 5, 3172-3178.

17 R. D. L. Smith, M. S. Prévot, R. D. Fagan, Z. Zhang, P. A. Sedach, M. K. J. Siu, S. Trudel and C. P. Berlinguette, Science, 2013, 340, 60-63.

18 T. Reier, Z. Pawolek, S. Cherevko, M. Bruns, T. Jones, D. Teschner, S. Selve, A. Bergmann, H. N. Nong, R. Schlögl, K. J. J. Mayrhofer and P. Strasser, J. Am. Chem. Soc., 2015, 137, 13031-13040.

19 V.-H. Tran, T. Yatabe, T. Matsumoto, H. Nakai, K. Suzuki, T. Enomoto, T. Hibino, K. Kaneko and S. Ogo, Chem. Commun., 2015, 51, 12589-12592.

20 W. H. Lee and H. Kim, Catal. Commun., 2011, 12, 408-411.

21 E. A. Paoli, F. Masini, R. Frydendal, D. Deiana, C. Schlaup, M. Malizia, T. W. Hansen, S. Horch, I. E. L. Stephens and I. Chorkendorff, Chem. Sci., 2015, 6, 190-196.

22 P. Lettenmeier, L. Wang, U. Golla-Schindler, P. Gazdzicki, N. A. Cañas, M. Handl, R. Hiesgen, S. S. Hosseiny, A. S. Gago and K. A. Friedrich, Angew. Chem., Int. Ed., 2016, 55, 742-746.

23 T. Reier, M. Oezaslan and P. Strasser, ACS Catal., 2012, 2, 1765-1772.

24 S. Cherevko, S. Geiger, O. Kasian, A. Mingers and K. J. J. Mayrhofer, J. Electroanal. Chem., 2016, 774, 102-110.

25 S. Cherevko, S. Geiger, O. Kasian, A. Mingers and K. J. J. Mayrhofer, J. Electroanal. Chem., 2016, 773, 69-78.

26 H. N. Nong, H. S. Oh, T. Reier, E. Willinger, M. G. Willinger, V. Petkov, D. Teschner and P. Strasser, Angew. Chem., Int. Ed., 2015, 54, 2975-2979.

27 Y. Pi, N. Zhang, S. Guo, J. Guo and X. Huang, Nano Lett., 2016, 16, 4424-4430.

28 P. Lettenmeier, J. Majchel, L. Wang, A. S. Gago and K. A. Friedrich, ECS Trans., 2016, 72, 1-9.

29 F. Polack, M. Silly, C. Chauvet, B. Lagarde, N. Bergeard, M. Izquierdo, O. Chubar, D. Krizmancic, M. Ribbens, J. P. Duval, C. Basset, S. Kubsky and F. Sirotti, AIP Conf. Proc., 2010, 1234, 185-188.

30 V. A. Saveleva, L. Wang, W. Luo, S. Zafeiratos, C. UlhaqBouillet, A. S. Gago, K. A. Friedrich and E. R. Savinova, J. Phys. Chem. Lett., 2016, 7, 3240-3245.

31 V. Pfeifer, T. E. Jones, J. J. Velasco Vélez, C. Massué, R. Arrigo, D. Teschner, F. Girgsdies, M. Scherzer, M. T. Greiner,
J. Allan, M. Hashagen, G. Weinberg, S. Piccinin, M. Hävecker, A. Knop-Gericke and R. Schlögl, Surf. Interface Anal., 2016, 48, 261-273.

32 W. Smekal, W. S. M. Werner and C. J. Powell, Surf. Interface Anal., 2005, 37, 1059-1067.

33 R. Guidelli, R. G. Compton, J. M. Feliu, E. Gileadi, J. Lipkowski, W. Schmickler and S. Trasatti, Pure Appl. Chem., 2014, 86, 245-258.

34 A. Minguzzi, O. Lugaresi, E. Achilli, C. Locatelli, A. Vertova, P. Ghigna and S. Rondinini, Chem. Sci., 2014, 5, 3591.

35 A. Damjanovic, A. Dey and J. O. M. Bockris, Electrochim. Acta, 1966, 11, 791-813.

36 J. O. Bockris and T. Otagawa, J. Phys. Chem., 1983, 87, 29602971.

37 G. Lodi, E. Sivieri, A. De Battisti and S. Trasatti, J. Appl. Electrochem., 1978, 8, 135-143.

38 H. G. Sanchez Casalongue, M. L. Ng, S. Kaya, D. Friebel, H. Ogasawara and A. Nilsson, Angew. Chem., Int. Ed., 2014, 53, 7169-7172.

39 C. P. De Pauli and S. Trasatti,J. Electroanal. Chem., 1995, 396, 161-168.

40 B. E. Conway and J. Mozota, Electrochim. Acta, 1983, 28, 9-16. 41 P. G. Pickup and V. I. Birss, J. Electroanal. Chem., 1987, 220, 83-100.

42 J. Juodkazyte, B. Šebeka, G. Stalnionis and K. Juodkazis, Electroanalysis, 2005, 17, 1734-1739.

43 R. Koetz and H. Neff, J. Electrochem. Soc., 1984, 131, 72-76.

44 R. Koetz, H. J. Lewerenz, P. Brüesch and S. Stucki, J. Electroanal. Chem. Interfacial Electrochem., 1983, 150, 209216.

45 V. Pfeifer, T. E. Jones, J. J. Velasco Vélez, R. Arrigo, S. Piccinin, M. Hävecker, A. Knop-Gericke and R. Schlögl, Chem. Sci., 2017, 8, 2143-2149.

46 S. Cherevko, S. Geiger, O. Kasian, N. Kulyk, J. P. Grote, A. Savan, B. R. Shrestha, S. Merzlikin, B. Breitbach, A. Ludwig and K. J. J. Mayrhofer, Catal. Today, 2016, 262, 170-180.

47 P. Lettenmeier, R. Wang, R. Abouatallah, S. Helmly, T. Morawietz, R. Hiesgen, S. Kolb, F. Burggraf, J. Kallo, A. S. Gago and K. A. Friedrich, Electrochim. Acta, 2016, 210, 502-511.

48 P. Lettenmeier, R. Wang, R. Abouatallah, S. Helmly, T. Morawietz, R. Hiesgen, S. Kolb, F. Burggraf, J. Kallo, A. S. Gago and K. A. Friedrich, Electrochim. Acta, 2016, 210, 502-511.

49 S. M. Alia, B. Rasimick, C. Ngo, K. C. Neyerlin, S. S. Kocha, S. Pylypenko, H. Xu and B. S. Pivovar, J. Electrochem. Soc., 2016, 163, F3105-F3112.

50 C. Chen, Y. Kang, Z. Huo, Z. Zhu, W. Huang, H. L. Xin, J. D. Snyder, D. Li, J. A. Herron, M. Mavrikakis, M. Chi, K. L. More, Y. Li, N. M. Markovic, G. A. Somorjai, P. Yang and V. R. Stamenkovic, Science, 2014, 343, 1339-1343.

51 Z. Li, R. Yu, J. Huang, Y. Shi, D. Zhang, X. Zhong, D. Wang, Y. Wu and Y. Li, Nat. Commun., 2015, 6, 8248.

52 L. Wang, V. A. Saveleva, S. Zafeiratos, E. R. Savinova, P. Lettenmeier, P. Gazdzicki, A. S. Gago and K. A. Friedrich, Nano Energy, 2017, 34, 385-391. 